\title{
Moving Photovoltaic Installations: Impacts of the Sampling Rate on Maximum Power Point Tracking Algorithms
}

\author{
Christian Schuss, Member, IEEE, Tapio Fabritius, Bernd Eichberger, and Timo Rahkonen, Member, IEEE
}

\begin{abstract}
This paper investigates the impact of the solar radiation level on the available output power of moving photovoltaic (PV) installations with the help of PV simulation models and real-world environmental data. For moving PV installations, for example on top of hybrid electric vehicles (HEVs) and batterypowered electric vehicles (BEVs), the sampling rate was 6,000 samples per second. We analyse the changes in the amount of solar radiation that can influence on the control of the operating voltage of photovoltaics within maximum power point tracking (MPPT) algorithms. We present recommendations for the sampling rate of environmental data which is used for PV simulation models. Furthermore, we discuss the update frequency of vital parameters of different MPPT techniques for controlling moving PV installations. Here, we concentrate on the degree of efficiency of the perturb and observe (P\&O) algorithm. In addition, we show how the sampling rate of environmental data influences the test criteria for MPPT algorithms.
\end{abstract}

Index Terms-accuracy, data acquisition, environmental data, maximum power point tracking, moving photvoltaic installations, resolution, sampling rate, solar energy, solar radiation level.

\section{INTRODUCTION}

$\mathbf{S}$ OLAR energy is one of the most promising alternatives [1], in particular to substitute energy gained from fossil fuels [2]. In future, for example, the opportunity is given to integrate photovoltaic (PV) cells into the roof of hybrid electric vehicles (HEVs) and battery-powered vehicles (BEVs) in order to extend the electrical operating driving range of these types of vehicles [3]. Similarly, a charging station powered by PV panels can be used to charge the high-voltage battery of a $\mathrm{BEV}$, for example [4].

Generally speaking, for new types of applications, PV simulation models are helpful in order to determine the potential maximum power of photovoltaics on one hand and the available output power under varying ambient conditions on the other. For example, when harvesting PV energy for wireless sensor network (WSN) nodes, the choice of power source is essential so that the target system does not run out of energy overnight [6]-[8]. The single diode model is an equivalent electric circuit used to model the photovoltaic cell and is commonly used in existing literature [7]-[10].

This work was financially supported by Infotech Oulu. Prof. Tapio Fabritius is partially funded by the Academy of Finland 6Genesis (6G) project.

C. Schuss, and T. Rahkonen are with the Circuits and Systems (CAS) Research Unit, University of Oulu, 90014 Oulu, Finland (e-mail: christian.schuss@oulu.fi).

B. Eichberger is with the Institute of Electronic Sensor Systems, Graz University of Technology, 8010 Graz, Austria.

Accepted Version February 19, 2019
The overall accuracy of the PV simulation is dependent upon two individual tasks. At first, we have to estimate unknown parameters within the model so that the equivalent circuit fits the real photovoltaics as well as possible [8][12]. In other words, we try to minimise the error between simulation and reality. Secondly, we can compute the output power $\left(P_{\text {out }}\right)$ and calculate the possible amount of energy of a PV installation with the help of environmental data, in particular the solar radiation level [5]. The time resolution of ambient data has an impact on the accuracy of the simulation as well. In [5], we investigated the impact of the sampling rate on the estimation of the amount of solar energy. The focus lied on the amount of solar radiation which can be absorbed on top of stationary PV installations.

The integration of PV cells into the roofs of HEVs and BEVs has enormous potential to change the way of transportation of our society [13]. A PV installation on top of the roof of a vehicle can provide power to the high-voltage battery [14], [15] and, thereby, reduce the amount of greenhouse gas emissions [16]. However, the available area on top of the roof of HEVs and BEVs is limited [16], [17]. It is worth noting that other areas than the roof of the vehicle, such as the side, the rear and the front of the vehicle, receive less irradiation [18]. Furthermore, the environmental conditions, in particular the rate of change of the solar radiation level, differ significantly for moving vehicles than for parked vehicles [18], [19].

In this paper, we present an improved measurement system which offers several advantages and benefits over the measurement setup used in [20]. At first, we have doubled the number of measurement probes to sense the solar radiation level $(\lambda)$ from 4 to 8 in order to obtain more detailed information on the shading conditions of the vehicle's roof and the PV installation. Secondly, we have increased the sampling rate from 50 samples per second to 6,000 samples per second. As a result, we are able to provide more precise information on the rate of change of the solar radiation level, in particular on the speed of changes and the time window of changes in the amount of irradiation.

The higher sampling rate than in previous research [20] allows us to demonstrate that the rate of change of the solar radiation level is significantly higher for the case of moving PV installations than for stationary PV installations. Generally speaking, a high rate of change of the solar radiation level imposes challenges for maximum power point tracking (MPPT) algorithms, which are used to modify the operating voltage based on changes in ambient conditions. If the solar radiation 
level alternates extremely rapidly, as it is the case for moving PV installations, MPPT techniques have enormous difficulties following these rapid changes. As a result, the degree of efficiency of the MPPT algoritm is reduced remarkably.

In addition, we extend the analyses presented in [20] related to PV simulation models and MPPT algorithms in several ways. With the help of a higher sampling rate of 6,000 samples per second, we illustrate in more detail how quickly the solar radiation level changes in the case of moving PV installations and how the rate of change is affected by the sample rate. Furthermore, we demonstrate how the sampling rate influences the estimation on the total amount of solar radiation available on top of moving PV installations. Moreover, we demonstrate how the rate of change affects the required update frequency of vital parameters of MPPT algorithms and which limitations are present for the update frequency of these vital parameters.

If the sampling rate is too small, the estimated amount of solar energy is either too low or too high. False estimations can have a negative impact on the design of applications. Furthermore, we concentrate on the update rate of vital parameters for MPPT techniques. On the example of the perturb and observe $(\mathrm{P} \& \mathrm{O})$ algorithm, we show that the update frequency for MPPT algorithms which is used for stationary PV installations is not sufficiently high enough in order to achieve the same high degree of efficiency for the case of moving PV installations.

The structure of this paper is as follows: Section II presents the measurement system. In Section III, we discuss the rate of change of the solar radiation level for stationary PV installations. Here, we discuss the test criteria for conventional MPPT algorithms. In Section IV, we present experimental results and analyse the influence of the sampling rate on the rate of change of the solar radiation level for the case of moving PV installations. In Section V, we verify the impact of the resolution of the solar radiation data on the simulation of the conventional $\mathrm{P} \& \mathrm{O}$ algorithm. We present discussions and conclusions in Section VI and VII.

\section{Measurement System}

In [5], we presented an accurate low-cost measurement probe for collecting data on the amount of solar radiation. The measurement probe itself consists of a monocrystalline silicion PV cell (size: 55 x $55 \mathrm{~mm}$ ) and was calibrated with the help of measurement instruments in the same way as in [21]. In contrast to previous research [20], we have doubled the number of measurement probes to obtain more precise information on the solar radiation level $(\lambda)$ on top of the roof of a vehicle, from 4 to 8, as illustrated in Fig. 1. In [20], probes were located in positions $1,3,6$, and 8 . In this research, we also placed probes in positions 2, 4, 5, and 7 .

Moreover, in contrast to [20], each of the measurement probes was sampled 6,000 times per second instead of 50 times per second. Data was collected with the help of the National Instruments (NI) 6009 data acquisition (DAQ) module and LabVIEW. The installation of the measurement setup on top of the roof of a vehicle is shown in Fig. 2. Due to the flat roof of the vehicle within the experiments, the alignment of each
TABLE I

DATA OF THE USED PV CELL IN THE MEASUREMENT PROBE

\begin{tabular}{|c|c|}
\hline Parameter & Value \\
\hline$P_{m p p}$ & $45 \mathrm{~mW}$ \\
\hline$V_{m p p}$ & $1.7 \mathrm{~V}$ \\
\hline$I_{m p p}$ & $35 \mathrm{~mA}$ \\
\hline$V_{o c}$ & $2.4 \mathrm{~V}$ \\
\hline$I_{s c}$ & $25 \mathrm{~mA}$ \\
\hline
\end{tabular}

AM1.5; $\lambda=1,000 \mathrm{~W} / \mathrm{m}^{2} ; T_{c}=25{ }^{\circ} \mathrm{C}$; standard test conditions (STC)

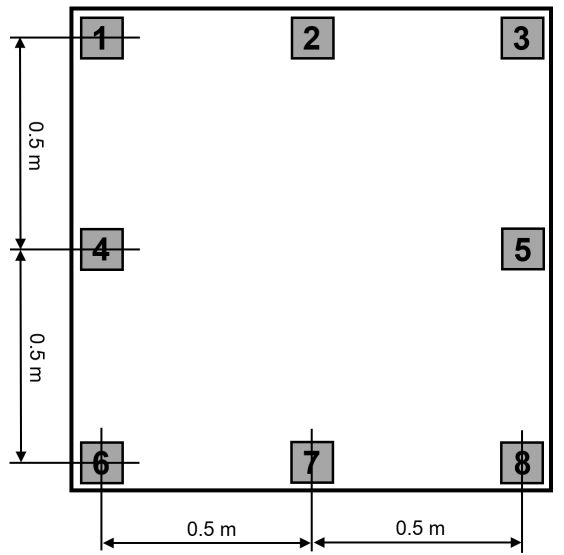

Fig. 1. Alignment of measurements probes to obtain the solar radiation level

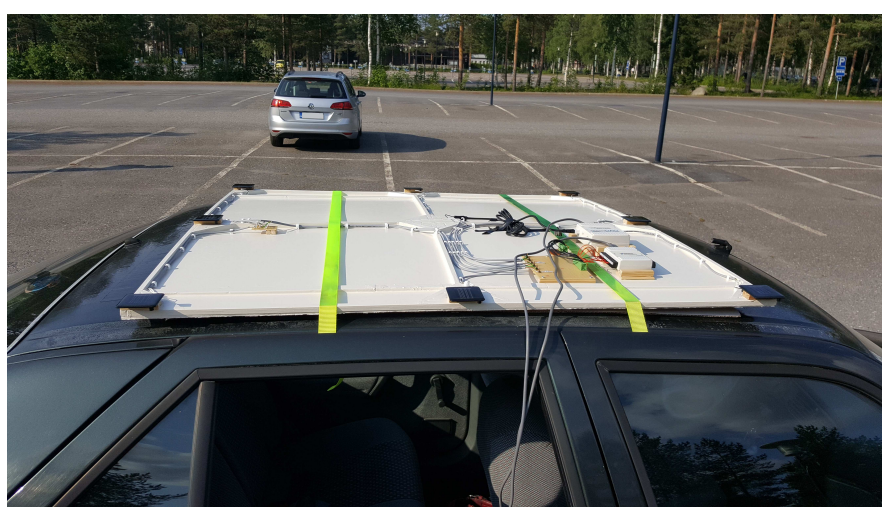

Fig. 2. Setup of measurements probes to obtain the solar radiation level

measurement probe was horizontal. In a horizontal installation, the measurement probe does not heat much. However, for reference, the temperature was recorded in the middle of the measurement setup.

\section{STATIONARY PV INSTALLATIONS}

\section{A. The Rate of Change of the Solar Radiation Level}

In this work, we focus on the rate of change of the solar radiation level $\left(r_{\lambda}\left[\frac{W}{m^{2}} / s\right]\right)$, more precisely on the slope of the solar radiation level $\left(\lambda\left[\mathrm{W} / \mathrm{m}^{2}\right]\right)$. In other words, we measure how quickly the solar radiation level varies for the PV cell or panel. It is worth noting that $r_{\lambda}$ is critical for the control of the operating voltage $\left(V_{o p}\right)$ of photovoltaics. $r_{\lambda}$ is defined as

$$
r_{\lambda}=\frac{\Delta \lambda}{\Delta t}
$$


For stationary PV installations, on a typical partly cloudysunny day, $r_{\lambda}$ can be as large as $150 \frac{\mathrm{W}}{\mathrm{m}^{2}} / \mathrm{s}$. Quickly changing environment conditions can be challenging for some MPPT algorithms, for example for the perturb and observe $(\mathrm{P} \& \mathrm{O})$ algorithm [22]. Thus, it is important that collected environmental data is suitable for evaluating the performance of MPPT algorithms. In this way, collected environmental data which is used within the simulation of MPPT algorithms should include similar alternation rates $\left(r_{\lambda}\right)$ as MPPT profiles.

However, if the time resolution of the solar radiation data is lowered, the speed of the upward and downward ramps is lowered as well. As an example, we take a look on a typical rising edge of the solar radiation data for a stationary PV installation. Fig. 3 illustrates the ramp in the original data form (obtained at 30 samples per second for a stationary PV installation [5] and shows how the speed of the ramp changes with different sampling rates if the irradiation is sampled each time at $t=5 \mathrm{~s}$. As seen in Fig. 3 the lower the sampling rate, the lower $r_{\lambda}$. The obtained maximum values for the upward ramp $\left(r_{\lambda, \max }\right)$ in Fig. 3 are as follows:

$$
\begin{array}{lll}
r_{\lambda, \max }=107 \frac{\mathrm{W}}{\mathrm{m}^{2}} / \mathrm{s} & & \text { original data } \\
r_{\lambda, \max }=62 \frac{W}{m^{2}} / \mathrm{s} & & 1 \text { sample every } 5 \mathrm{~s} \\
r_{\lambda, \max }=35 \frac{W}{m^{2}} / s & & 1 \text { sample every } 10 \mathrm{~s} \\
r_{\lambda, \max }=23 \frac{W}{m^{2}} / \mathrm{s} & & 1 \text { sample every } 15 \mathrm{~s} \\
r_{\lambda, \max }=17 \frac{W}{m^{2}} / \mathrm{s} & & 1 \text { sample every } 20 \mathrm{~s}
\end{array}
$$

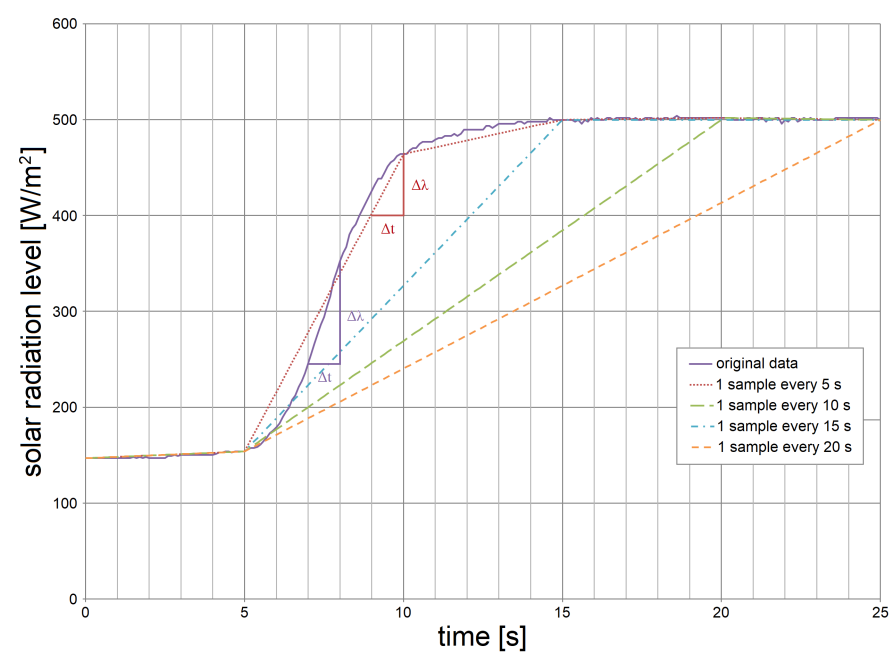

Fig. 3. Impact of the sampling rate on $r_{\lambda}$

The highest value for $r_{\lambda}$ is obtained during frequent changes between direct sunlight and cloud shadows and vice versa. By lowering sample frequency rates, more and more information on fast slopes of the solar radiation level is lost. As a result, the environmental data does not include the fast slopes which are present in test profiles for MPPT algorithms. Thus, for the case of stationary PV installations, when using environmental data for PV simulation models, which include the capability of simulating MPPT algorithms, the solar radiation level should be obtained at a high sampling rate of several samples per second.

\section{B. Testing Criteria of MPPT Algorithms}

The time resolution of environmental data also has an impact on the simulation of MPPT techniques. Basically, MPPT is required to ensure operating at or close to the maximum power point (MPP) and, thereby, obtaining as much power as possible from photovoltaics. Esram et al. summarised various approaches for carrying out MPPT and investigated differences between MPPT techniques [22].

Ropp et al. proposed a test profile for evaluating the performance of MPPT algorithms [23]. Their test protocol consists of slow slopes, fast slopes, and steady-state conditions, as illustrated in Fig. 3 Bründlinger et al. also suggested a test sequence for the MPPT techniques, where the PV inverter and its efficiency are included into their considerations and evaluations [24]. The focus of both papers lies on the changes of the solar radiation level $\left(\frac{\Delta \lambda}{\Delta t}\right)$. The question is how realistic such approaches are if we were to compare them against our measurement data.

We obtain, for example for $r_{\lambda}$,

from [23]:

for steady-state conditions: $\quad r_{\lambda}=0 \frac{\mathrm{W}}{\mathrm{m}^{2}} / \mathrm{s}$

for slow slopes: $\quad r_{\lambda}=10 \frac{\mathrm{W}}{\mathrm{m}^{2}} / \mathrm{s}$

for fast slopes: $\quad r_{\lambda}=200 \frac{W}{m^{2}} / s$

from [24]:

utmost case: $\quad r_{\lambda}=100 \frac{\mathrm{W}}{\mathrm{m}^{2}} / \mathrm{s}$

In [23], there are steady-state conditions at $200 \mathrm{~W} / \mathrm{m}^{2}, 600$ $\mathrm{W} / \mathrm{m}^{2}$, and $1000 \mathrm{~W} / \mathrm{m}^{2}$, while in [24] no steady-state conditions are considered. However, in [24], the solar radiation level varies between a minimum and a maximum solar radiation level ( $\lambda_{\min }$ and $\left.\lambda_{\max }\right)$ for $n$ repetitions. Thus, the ramp gradient ranges from $0.5 \frac{W}{m^{2}} / s$ up to $100 \frac{W}{m^{2}} / s$ as the utmost case.

The sampling rate influences the definition of a suitable test pattern for an MPP tracker based on the length of $r_{\lambda}$. On a typical partly cloudy, partly sunny day [5], the solar radiation level alternates frequently between a minimum, an intermediate and a maximum level. Naturally, these levels are not constant throughout the day. However, the intermediate level makes the test profile in [23] more practical than the pattern proposed in [24].

\section{Moving PV Installations}

\section{A. Measurements Setup}

The sample rate of solar radiation data is crucial for evaluating the opportunity for solar energy production in new kinds of environments and new types of applications. For example, solar energy can be of interest for powering portable and wearable devices such as mobile phones [25]. In previous research, we investigated the possibility to extend the electrical driving distance of battery-powered electric vehicles (BEVs) and hybrid electric vehicles (HEVs) with the help of PV installations on top of a vehicle's roof [3].

In the case of moving PV installations, MPPT algorithms have to react and respond to the given ambient conditions. Hence, we analysed the alternation rate of the irradiation on 
top of moving objects such as vehicles. We installed measurement probes horizontally on the roof of a vehicle, as shown in Fig. 2 Fig. 4 illustrates the setup of the measurements given in two streets in the City of Oulu, Finland, while Fig. 5 shows the ambient conditions in this street (from the starting point of view towards end point 1). Here, firstly, the irradiation was recorded by driving from north to south from the school to the chapel (end point 1).

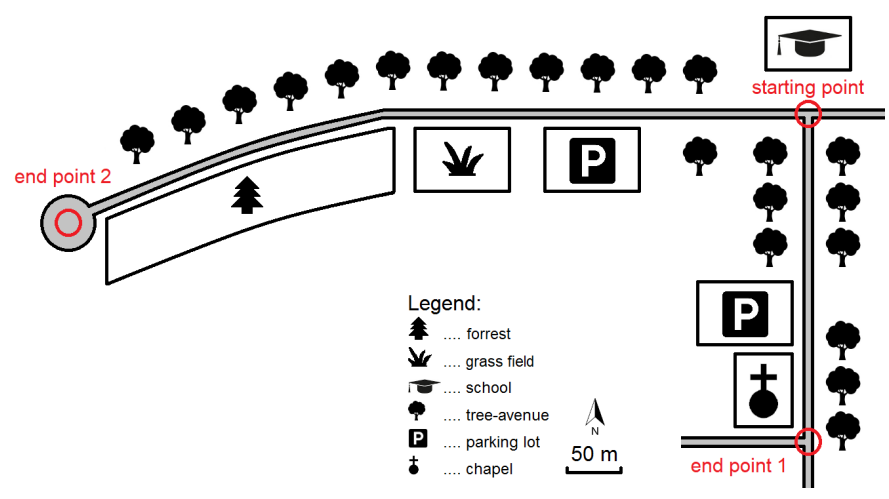

Fig. 4. Map of the streets for the measurements

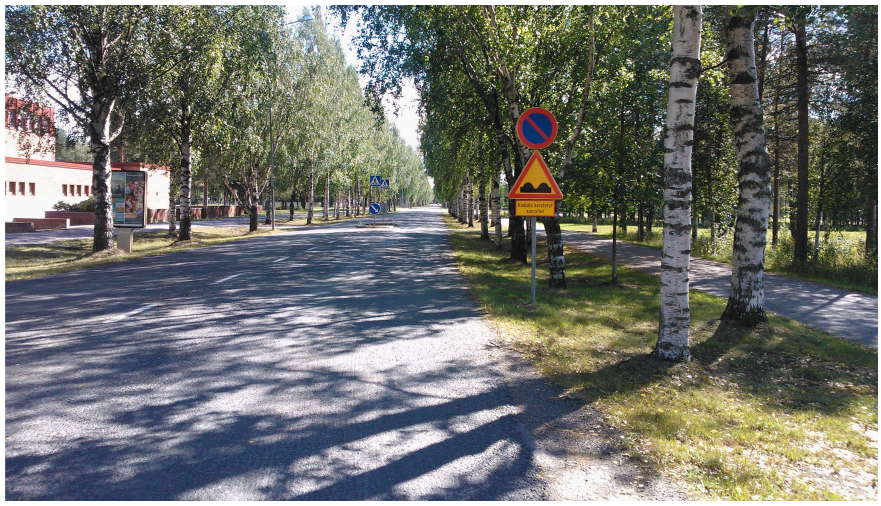

Fig. 5. Ambient conditions of the street for the measurements

\section{B. Measurements Results}

When driving from the starting point to end point 1 , in other words from the North to the South, at the beginning, the vehicle was passing through a tree-avenue which caused frequent changes in the amount of irradiation. Afterwards, the vehicle was driving next to a parking lot which provided no shading to the roof of the vehicle. The speed of the vehicle was approximately constant at $30 \mathrm{~km} / \mathrm{h}$ and the driving distance was about $300 \mathrm{~m}$. The measurement was repeated three times to ensure that the collected environmental data is not random.

In [20] and [26], we sampled each measurement probe at 50 times per second. In this research, we increased the sampling rate to 6,000 times per second. Fig. 6 shows the measurement results obtained on the $26^{\text {th }}$ of July at $4 \mathrm{pm}$, while Fig. 7 presents the results collected on the $31^{\text {st }}$ of July at $2 \mathrm{pm}$. Unfortunately, it is not possible to control weather conditions such as the wind speed for measurements in outdoor environments. Hence, measurements were carried out on different days on which direct sunlight without cloud coverage was available in order to obtain a more information on the ambient conditions for moving PV installations.

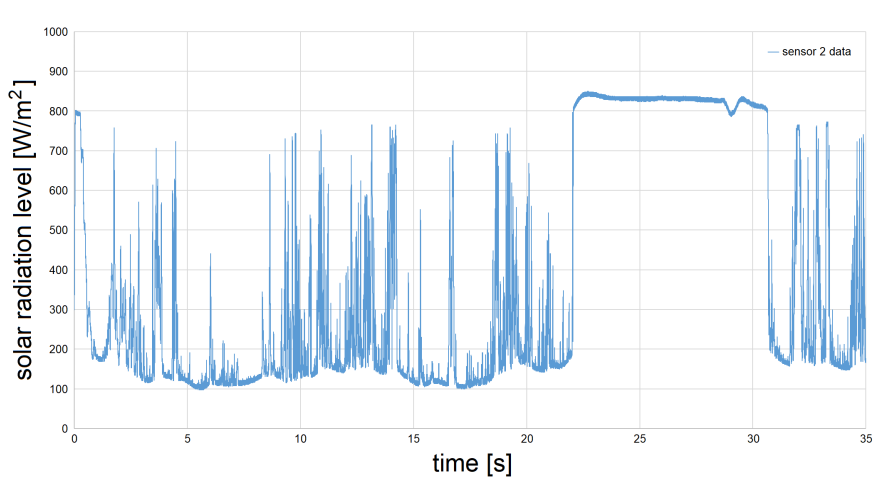

Fig. 6. Measurement data obtained on the $26^{\text {th }}$ of July, probe number 2

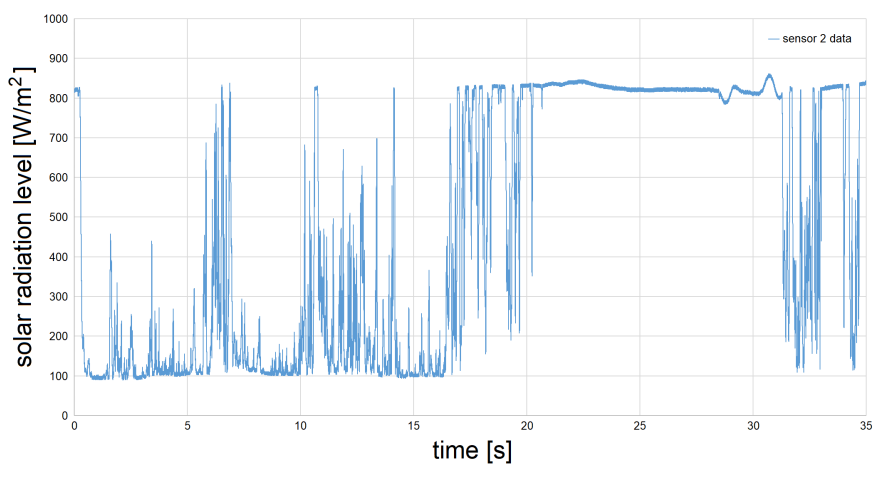

Fig. 7. Measurement data obtained on the $31^{\text {st }}$ of July, probe number 2

Furthermore, measurements were repeated immediately afterwards to obtain several measurement sets within similar ambient conditions. It is worth noting that the vehicle speed was also not exactly constant. Tables II and III present the available weather information, which was obtained from the Finnish Meteorological Institute and the local weather station operated by the VTT Technical Research Centre of Finland and Vaisala Oyj, for the days when experiments were carried out.

TABLE II

AVAILABLE WEATHER DATA FOR THE $26^{\mathrm{TH}}$ OF JULY, 4 PM

\begin{tabular}{|l|l||l|l|}
\hline Air temperature & $19{ }^{\circ} \mathrm{C}$ & Wind speed & $6 \frac{\mathrm{m}}{\mathrm{s}}$ \\
\hline Relative humidity & $79 \%$ & Gust speed & $9 \frac{\mathrm{m}}{\mathrm{s}}$ \\
\hline Nitrogen dioxide $\left(\mathrm{NO}_{2}\right)$ & $2 \frac{\mu g}{\mathrm{~m}^{3}}$ & Ozone $\left(\mathrm{O}_{3}\right)$ & $56 \frac{\mu g}{\mathrm{~m}^{3}}$ \\
\hline Particulate matter $<10 \mu \mathrm{m}$ & $9 \frac{\mu g}{\mathrm{~m}^{3}}$ & UV index & 2 \\
\hline
\end{tabular}

TABLE III

AVAILABLE WEATHER DATA FOR THE $31^{\text {ST }}$ OF JULY, 2 PM

\begin{tabular}{|l|l||l|l|}
\hline Air temperature & $19^{\circ} \mathrm{C}$ & Wind speed & $0 \frac{\mathrm{m}}{\mathrm{s}}$ \\
\hline Relative humidity & $86 \%$ & Gust speed & $2 \frac{\mathrm{m}}{\mathrm{s}}$ \\
\hline Nitrogen dioxide $\left(\mathrm{NO}_{2}\right)$ & $2 \frac{\mu g}{\mathrm{~m}^{3}}$ & Ozone $\left(\mathrm{O}_{3}\right)$ & $69 \frac{\mu g}{\mathrm{~m}^{3}}$ \\
\hline Particulate matter $<10 \mu \mathrm{m}$ & $8 \frac{\mu g}{\mathrm{~m}^{3}}$ & UV index & 3 \\
\hline
\end{tabular}




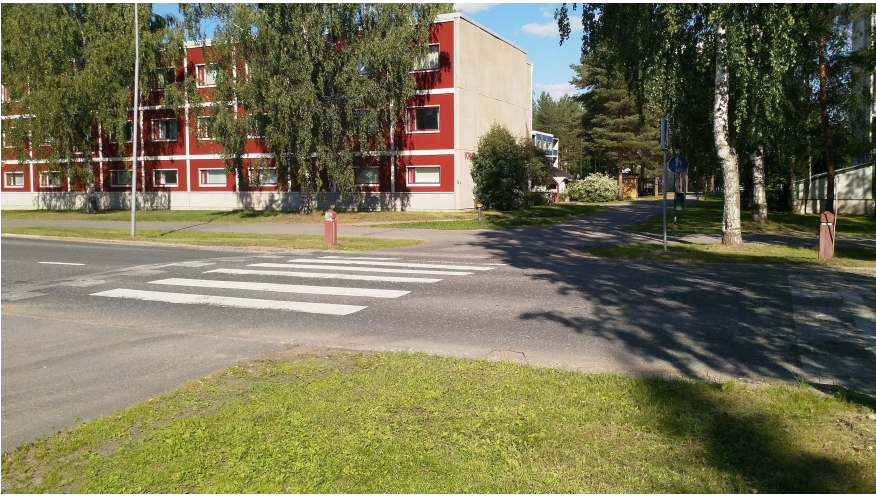

Fig. 8. Shading and diffuse radiation due to tree leaves

When comparing the measurement data obtained with the probe in position 2 from the two days with each other, we can see a difference in the solar radiation level obtainable under diffuse radiation. While the average minimum solar radiation level $\left(\bar{\lambda}_{\min }\right)$ was about $100 \mathrm{~W} / \mathrm{m}^{2}$ on the $31^{\text {st }}$ of July, $\bar{\lambda}_{\min }$ was about $150 \mathrm{~W} / \mathrm{m}^{2}$ on the $26^{\text {th }}$ of July. This difference can be caused by changes in reflectance, transmittance and absorptance of sunlight by tree leaves which are affected by the air temperature, relative humidity, wind and gust speed (leaf area index, gap fraction) as well as other ambient conditions such as particles and aerosols in the air [27]-[29]. For both days, the average maximum solar radiation level $\left(\bar{\lambda}_{\max }\right)$ was about $800 \mathrm{~W} / \mathrm{m}^{2}$ (horizontal level).

In Figs. 6 and 7, a drop in the solar radiation level can be observed at $t=29 \mathrm{~s}$. This short decrease and increase in the solar radiation level is due to a bump at a zebra crossing which is shown in Fig. 8 When the vehicle passes the upwards bump, the roof changes the alignment towards the sun (e.g. the roof phases slightly away from the sun) and, thus, the available irradiation on top of the roof changes. In Fig. 9, on the $31^{\text {st }}$ of July, an increase and decrease of the solar radiation level can be observed at $t=31 \mathrm{~s}$ as the vehicle passes the downwards bump of the zebra crossing (e.g. the roof phases slightly towards the sun). As seen in Figs. 6 and 8 , on the $26^{\text {th }}$ of July, the downwards bump of the zebra crossing was shaded and, thus, is not visible in the measurement data.

The aim of this research was to identify the rate of change of the solar radiation level $\left(r_{\lambda}\right)$ for moving PV installations and the suitable sampling rate for obtaining environmental data. Fig. 9 shows the upwards ramp which occurs at about $t=22$ $\mathrm{s}$ when the vehicle reaches the parking lot. At this time, the roof of the vehicle got completely exposed to direct sunlight. As seen in Fig. 9, the probes 1-8 reach the maximum solar radiation level $\left(\lambda_{\max }\right)$ at different times. At first, the front of the roof of the vehicle, more precisely probe 1-3 reach $\lambda_{\max }$, then probe 4 and 5 , followed by probe 6-8. Even between probes $1-3,4$ and 5 , as well as 6-8, a difference can be noticed. Due to the diagonal shading of the street, seen in Fig. 8 , probe 1 reaches $\lambda_{\max }$ slightly before probe 2 and 3 , for example.

In contrast to MPPT profiles discussed in Section III, the rate of change $\left(r_{\lambda}\right)$ is not linear, in other words does not increase on a constant basis, from $\lambda_{\min }$ and $\lambda_{\max }$. In previous

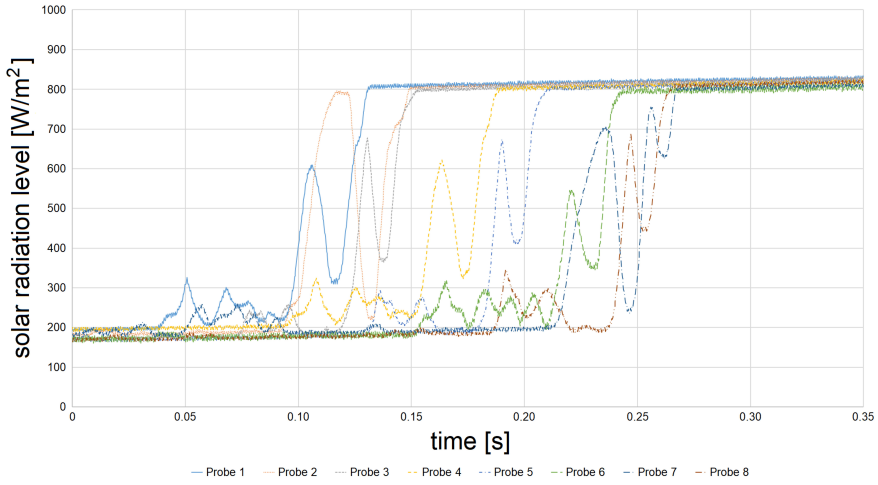

Fig. 9. Upwards ramp on the $26^{\text {th }}$ of July at about $t=22 \mathrm{~s}$, probe $1-8$

research [20], we identified the time window for the rate of change in solar radiation level. While the time window of variations in the solar radiation level is in seconds for stationary PV installations, it is in milliseconds for moving PV installations. In the obtained measurement data, $r_{\lambda}$ varies between 0 and $125 \frac{\mathrm{W}}{\mathrm{m}^{2}} / \mathrm{ms}$. For the upwards ramp at $t=22$ $\mathrm{s}$, from $\lambda_{\min }$ and $\lambda_{\max }$, the maximum alternating rate $\left(r_{\lambda, \max }\right)$ is about $90 \frac{\mathrm{W}}{\mathrm{m}^{2}} / \mathrm{ms}$. For example, for probe 2, the following values for $r_{\lambda, \max }$ were obtained:

$$
\begin{array}{lll}
r_{\lambda, \max }=88.32 \frac{W}{m^{2}} / m s & & 6,000 \text { samples } / \mathrm{s} \\
r_{\lambda, \max }=88.32 \frac{W}{m^{2}} / m s & & 3,000 \text { samples } / \mathrm{s} \\
r_{\lambda, \max }=88.32 \frac{W}{m^{2}} / m s & & 1,000 \text { samples } / \mathrm{s} \\
r_{\lambda, \max }=80.53 \frac{W}{m^{2}} / m s & & 500 \text { samples } / \mathrm{s} \\
r_{\lambda, \max }=41.56 \frac{W}{m^{2}} / m s & & 100 \text { samples } / \mathrm{s} \\
r_{\lambda, \max }=25.80 \frac{W}{m^{2}} / m s & & 50 \text { samples } / \mathrm{s}
\end{array}
$$

Hence, we recommend a sampling rate of at least 500 samples/s in order to obtain the rate of change of the solar radiation level in a suitable accuracy. As seen in Figs. 6 and 7. the solar radiation level varies between a minimum solar radiation level $\left(\lambda_{\min }\right)$ of 100 to $150 \mathrm{~W} / \mathrm{m}^{2}$ (depending on the ambient conditions) and a maximum solar radiation level $\left(\lambda_{\max }\right)$ of about $800 \mathrm{~W} / \mathrm{m}^{2}$. It is worth noting that values for $\lambda_{\min }$ and $\lambda_{\max }$ depend on the geographical location and time of the year, as shown in Table IV

TABLE IV

EXAMPLES FOR $\lambda_{\text {MIN }}$ AND $\lambda_{\text {MAX }}$ (HORIZONTAL LEVEL)

\begin{tabular}{|c|c|c|c|}
\hline Location & Month & $\lambda_{\min }$ & $\lambda_{\max }$ \\
\hline Maceió, Brazil 31 & February & $200 \mathrm{~W} / \mathrm{m}^{2}$ & $1,200 \mathrm{~W} / \mathrm{m}^{2}$ \\
\hline Milan, Italy 11 & May & $100 \mathrm{~W} / \mathrm{m}^{2}$ & $900 \mathrm{~W} / \mathrm{m}^{2}$ \\
\hline Lindenberg, Germany 32 & June & $150 \mathrm{~W} / \mathrm{m}^{2}$ & $1,000 \mathrm{~W} / \mathrm{m}^{2}$ \\
\hline Oulu, Finland 20 & July & $100 \mathrm{~W} / \mathrm{m}^{2}$ & $800 \mathrm{~W} / \mathrm{m}^{2}$ \\
\hline Maceió, Brazil 31 & July & $200 \mathrm{~W} / \mathrm{m}^{2}$ & $1,400 \mathrm{~W} / \mathrm{m}^{2}$ \\
\hline Trieste, Italy 30 & September & $150 \mathrm{~W} / \mathrm{m}^{2}$ & $900 \mathrm{~W} / \mathrm{m}^{2}$ \\
\hline
\end{tabular}

Figs. 10 and 11 illustrate the rate of change of the solar radiation level $\left(r_{\lambda}\right)$ which was obtained on the $31^{\text {st }}$ of July. In Fig. 10, the speed of the vehicle $(v)$ was $30 \mathrm{~km} / \mathrm{h}$, while the vehicle speed was $40 \mathrm{~km} / \mathrm{h}$ in Fig. 11. It can be seen that an 


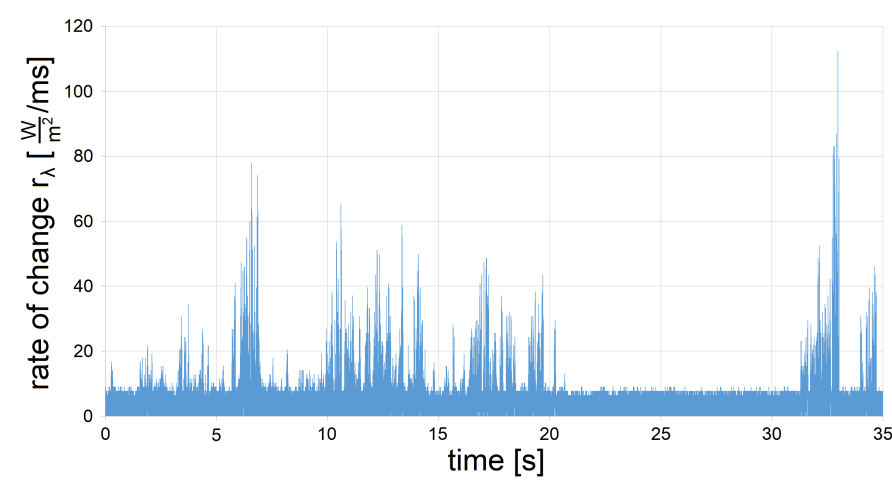

Fig. 10. $r_{\lambda}$ obtained on the $31^{\text {st }}$ of July, probe number $2(v=30 \mathrm{~km} / \mathrm{h})$

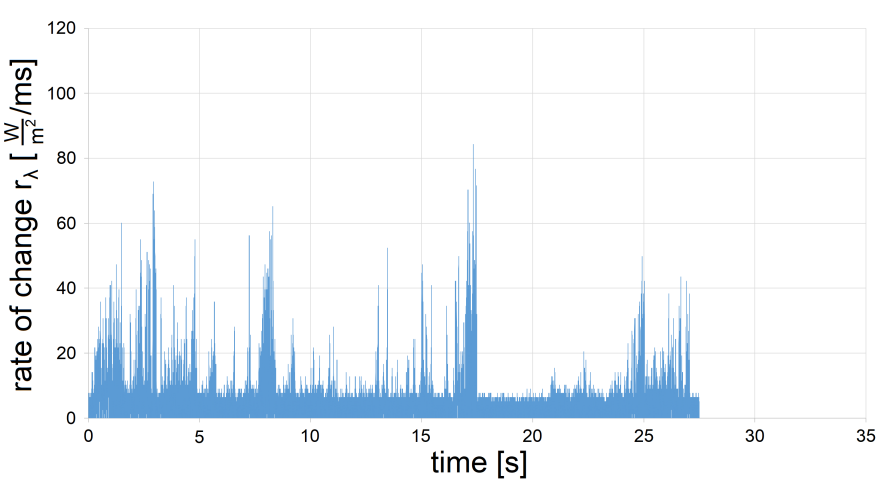

Fig. 11. $r_{\lambda}$ obtained on the $31^{\text {st }}$ of July, probe number $2(v=40 \mathrm{~km} / \mathrm{h})$

increase in vehicle speed by $10 \mathrm{~km} / \mathrm{h}$, shortens the duration of the measurement by about $7 \mathrm{~s}$. However, the increase in the speed of the vehicle does not result in an increase of $r_{\lambda}$. Instead, $r_{\lambda, \max }$ was $112.39 \frac{W}{m^{2}} / m s$ at $v=30 \mathrm{~km} / \mathrm{h}$ and $r_{\lambda, \max }$ was $84.29 \frac{\mathrm{W}}{\mathrm{m}^{2}} / \mathrm{ms}$ at $v=40 \mathrm{~km} / \mathrm{h}$.

As the solar radiation level does not increase on a linear basis, it is difficult to design a possible MPPT test profile for moving PV installations. When analysing the obtained measurement data, it was found out that steady-state conditions at intermediate levels (as in Fig. 3 [23]) are not realistic in practice and, thus, should not be considered for a potential MPPT test profile. However, the solar radiation level can increase to intermediate levels of about 400 to $600 \mathrm{~W} / \mathrm{m}^{2}$, but does not remain at this level.

For example, when driving through a tree-avenue, fast and frequent changes between diffuse radiation $\left(\lambda_{\min }\right)$, partly shaded/sunny conditions $\left(\lambda_{\text {int }}\right)$ and direct sunlight $\left(\lambda_{\max }\right)$ can occur. These variations in $\lambda$ are not constant, in other words they cannot be represented as a sequence of $n$ repetitions as in [24]. Hence, it is challenging to design a MPPT test profile which includes the same conditons on the rate of change of the solar radiation level as in real environmental data. Therefore, for the verification of the degree of efficiency of MPPT algorithms, we recommend to use collected data on the solar radiation level directly as input data.

Beside the influence on the rate of change of the solar radiation level, the sampling rate has also an impact on the overall estimation of the available irradiation [5]. On the example of the measurement data obtained on the $31^{\text {st }}$ of
July $(v=30 \mathrm{~km} / \mathrm{h})$, during the frequent changes of diffuse radiation and direct sunlight, a difference $(|\Delta|)$ in the estimated irradiation occurs when the data obtained at $6,000 \mathrm{samples} / \mathrm{s}$ is downsampled. Hence, a sampling rate of 500 samples/s is appropriate in order to minimise the difference in the estimated available irradiation, as illustrated in Fig. 12 for $v=30 \mathrm{~km} / \mathrm{h}$ and Fig. 13 for $v=40 \mathrm{~km} / \mathrm{h}$.

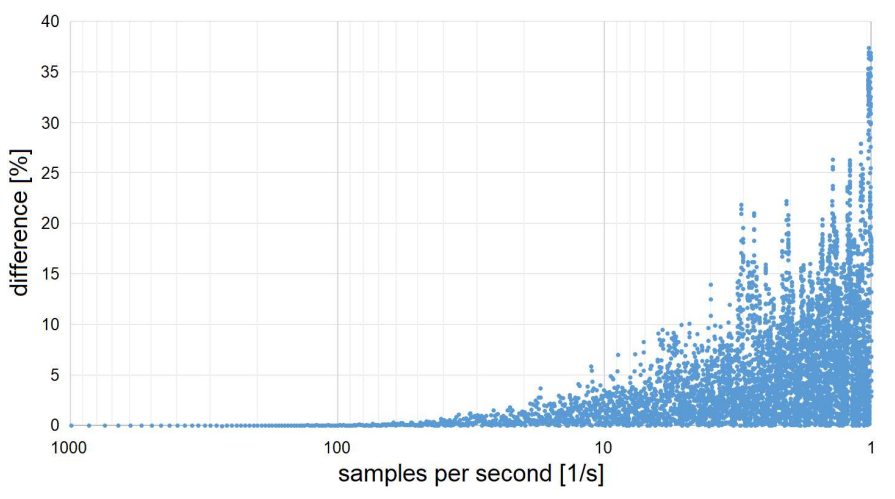

Fig. 12. $|\Delta|[\%]$ on the $31^{\text {st }}$ of July $(v=30 \mathrm{~km} / \mathrm{h})$

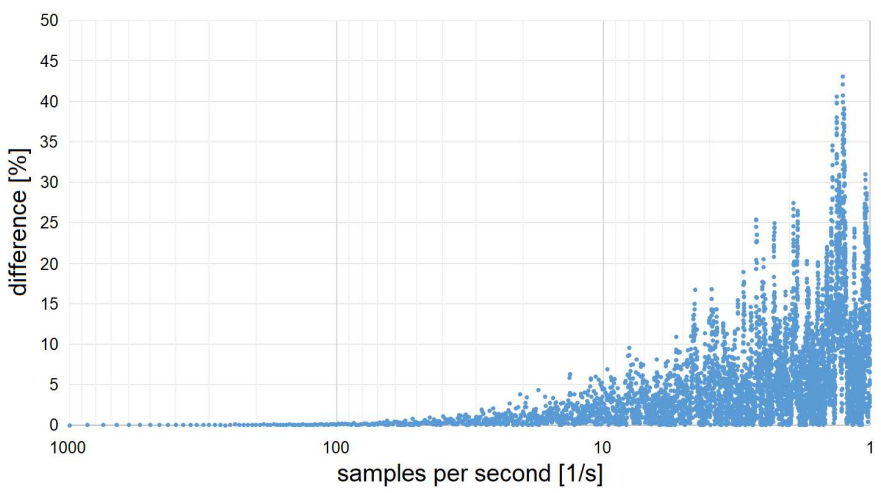

Fig. 13. $|\Delta|[\%]$ on the $31^{\text {st }}$ of July $(v=40 \mathrm{~km} / \mathrm{h})$

When driving in other directions, the ambient conditions and the types of surrounding objects can vary and so does the maximum rate of change $\left(r_{\lambda, \max }\right)$. As illustrated in Fig. 4, we carried out measurements also by driving from the South to the North (end point 1 to starting point) as well as from the East to the West (starting point to end point 2) and vice versa. When driving from the East to the West, at the beginning, the vehicle passes a tree avenue which becomes a single sided avenue of trees after a few metres. While the parking lot and grass field provide more sunlight to the roof of the vehicle, the forest provide more shadow to the vehicle.

Table $\mathrm{V}$ summarises the collected measurement data for probe 2. As seen in Table $\mathrm{V}$, for $v=30$ to $50 \mathrm{~km} / \mathrm{h}, r_{\lambda, \max }$ ranges from about $35 \frac{\mathrm{W}}{\mathrm{m}^{2}} / \mathrm{ms}$ up to about $115 \frac{\mathrm{W}}{\mathrm{m}^{2}} / \mathrm{ms}$. Other probes provide different, but similar values for the rate of change of the solar radiation level as the shading of the roof is unequally distributed. As seen in Fig. 9 shading due surrounding objects causes variations in the available irradiation at different times. However, it can be said that the output power of the moving PV installation varies significantly in driving conditions in comparison to parked conditions. 
TABLE V

$r_{\lambda, \max }$ FOR DIFFERENT DRIVING DIRECTIONS AND DRIVING SPEEDS

\begin{tabular}{|l|l|}
\hline Direction & $r_{\lambda, \max }$ (probe 2$)$ \\
\hline North to South, $31^{\text {st }}$ of July $(v=30 \mathrm{~km} / \mathrm{h})$ & $112.39 \frac{W}{m^{2}} / m s$ \\
\hline South to North, $31^{\text {st }}$ of July $(v=30 \mathrm{~km} / \mathrm{h})$ & $42.26 \frac{W}{m^{2}} / m s$ \\
\hline North to South, $31^{\text {st }}$ of July $(v=40 \mathrm{~km} / \mathrm{h})$ & $84.29 \frac{W}{m^{2}} / m s$ \\
\hline South to North, $31^{\text {st }}$ of July $(v=40 \mathrm{~km} / \mathrm{h})$ & $46.22 \frac{W}{m^{2}} / m s$ \\
\hline East to West, $26^{\text {th }}$ of July $(v=30 \mathrm{~km} / \mathrm{h})$ & $36.63 \frac{W}{m^{2}} / m s$ \\
\hline West to East, $26^{\text {th }}$ of July $(v=30 \mathrm{~km} / \mathrm{h})$ & $50.91 \frac{W}{m^{2}} / m s$ \\
\hline East to West, $26^{\text {th }}$ of July $(v=50 \mathrm{~km} / \mathrm{h})$ & $50.39 \frac{W}{m^{2}} / m s$ \\
\hline West to East, $26^{\text {th }}$ of July $(v=50 \mathrm{~km} / \mathrm{h})$ & $64.94 \frac{W}{m^{2}} / m s$ \\
\hline
\end{tabular}

\section{Simulation of the Conventional P\&O ALGORITHM}

\section{A. Description of the Investigated MPPT algorithm}

We analysed the performance of the $\mathrm{P} \& \mathrm{O}$ algorithm, since this MPPT algorithm is one of the most commonly used in practice. Here, the operating voltage $\left(V_{o p}\right)$ is alternated based on the outcomes of the previous alternation. $V_{o p}$ is either increased or decreased, depending on whether the current output power increased or decreased in comparison to the previous measured output power [22].

\section{B. Description of the Simulation Setup}

A PV simulation model was created in MATLAB ${ }^{\circledR}$ for verifying the impact of fast changing irradiation which occurs on top of moving objects and calculating the efficiency of the $\mathrm{P} \& \mathrm{O}$ algorithm. The single diode model was used as an equivalent electric circuit for the simulation of one PV cell. A standard monocrystalline PV cell was used for the simulation model which had the same characteristics as the PV cell used in the measurement probe. Table $\mathrm{VI}$ summarises the available data from the manufacturer Blue Chip Energy GmbH.

TABLE VI

Data of THE BLUE ChIP PV CELL

\begin{tabular}{|c|c|}
\hline Parameter & Value \\
\hline$P_{m p p}$ & $4.140 \mathrm{~W}$ \\
\hline$V_{m p p}$ & $0.515 \mathrm{~V}$ \\
\hline$I_{m p p}$ & $8.039 \mathrm{~A}$ \\
\hline$V_{o c}$ & $0.613 \mathrm{~V}$ \\
\hline$I_{s c}$ & $8.602 \mathrm{~A}$ \\
\hline
\end{tabular}

AM1.5; $\lambda=1,000 \mathrm{~W} / \mathrm{m}^{2} ; T_{c}=25{ }^{\circ} \mathrm{C} ;$ standard test conditions (STC)

In experiments, it was observed that changes in the PV cell temperature $\left(\frac{d T_{c}}{d t}\right)$ are minor. At $\lambda=800 \mathrm{~W} / \mathrm{m}^{2}$, a temperature variation of $0.1{ }^{\circ} \mathrm{C}$ causes a change in the available output power $\left(P_{\text {out }}\right)$ of $0.04 \%$, while a solar radiation level variation of $10 \mathrm{~W} / \mathrm{m}^{2}$ causes a change in $P_{\text {out }}$ of $1.32 \%$. Thus, for simplicity, $T_{c}$ was assumed to be constant at $25{ }^{\circ} \mathrm{C}$ in the simulation model. In contrast to [7], [9], we used an analytical model due to the large file size of the solar radiation data.

Firstly, a data base of I-V curves in the form of a lockup table was created for irradiation levels from 1 to 1,000
$\mathrm{W} / \mathrm{m}^{2}$. In this way, the measurement data on the amount of solar radiation can be used directly as an input parameter for calculations. Secondly, the model obtains the solar radiation level from the measurement file. Then, the power in the MPP $\left(P_{m p p}\right)$ was calculated as well as the output power at other voltages than the voltage in the MPP $\left(V_{m p p}\right)$. As a result, the output power $\left(P_{\text {out }}\right)$ and the efficiency of the MPPT algorithm $\left(\eta_{m p p t}\right)$ were obtained.

\section{Calculating the Efficiency of the $P \& O$ Algorithm}

In practise, it is not possible to continuously operate always in the MPP. Thus, the obtained output power $\left(P_{\text {out }}\right)$ is lower than the power which was available in the MPP $\left(P_{m p p}\right)$ [22]. The degree of efficiency of the MPPT algorithm $\left(\eta_{\text {mppt }}\right)$ can be obtained as follows:

$$
\eta_{m p p t}=\frac{\int_{0}^{T} P_{\text {out }} d t}{\int_{0}^{T} P_{\text {mpp }} d t} \times 100
$$

\section{Analysing the Performance of the $P \& O$ Algorithm}

The aim of this research was to verify the loss in efficiency of the $\mathrm{P} \& \mathrm{O}$ algorithm if the same update frequency of the vital parameter of the MPPT algorithm is used within moving PV installations as for stationary PV installations. However, it is worth noting that there are modified versions of the $\mathrm{P} \& \mathrm{O}$ algorithm available, which can cope better with fast changing ambient conditions. Figs. 14/16 illustrate the obtained efficiency of the $\mathrm{P} \& \mathrm{O}$ algorithm $\left(\eta_{m p p t}\right)$ for different sample rates of $P_{\text {out }}$ for the $26^{\text {th }}$ of July $(v=30 \mathrm{~km} / \mathrm{h})$ and $31^{\text {st }}$ of July $(v$ $=30 \mathrm{~km} / \mathrm{h}$ and $v=40 \mathrm{~km} / \mathrm{h}$ ). The focus lies on the part of the measurement data in which frequent changes of the ambient conditions are taken place ( $t=0 \mathrm{~s}$ to $t=20 \mathrm{~s}$ ).

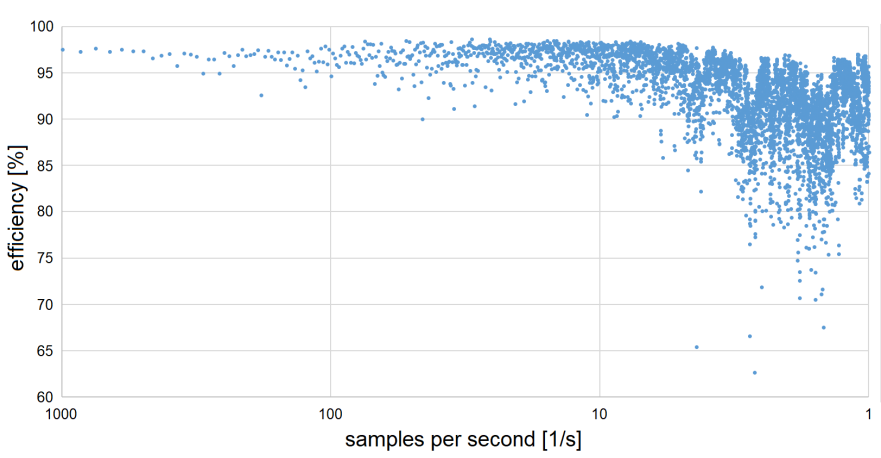

Fig. 14. $\mathrm{P} \& \mathrm{O}$ algorithm efficiency $\left(\eta_{m p p t}\right), 26^{\text {th }}$ of July $(v=30 \mathrm{~km} / \mathrm{h})$

It can be seen that reducing the update frequency of $P_{\text {out }}$ results in a decrease of the efficiency of the $\mathrm{P} \& \mathrm{O}$ algorithm $\left(\eta_{m p p t}\right)$. When updating $P_{\text {out }}$ at 6,000 samples/s, $\eta_{m p p t}$ is about 99.5\%. Updating $P_{\text {out }}$ at 100 samples/s results in an efficiency of about $95 \%$. However, in practice, such a high update frequency of $P_{\text {out }}$ is difficult to achieve. The string of PV cells or PV panel would need to be disconnected too many times from the power converter to obtain the current output power of the PV installation.

A small reference PV cell or panel with the same characteristics as the main PV panel could be used for obtaining 


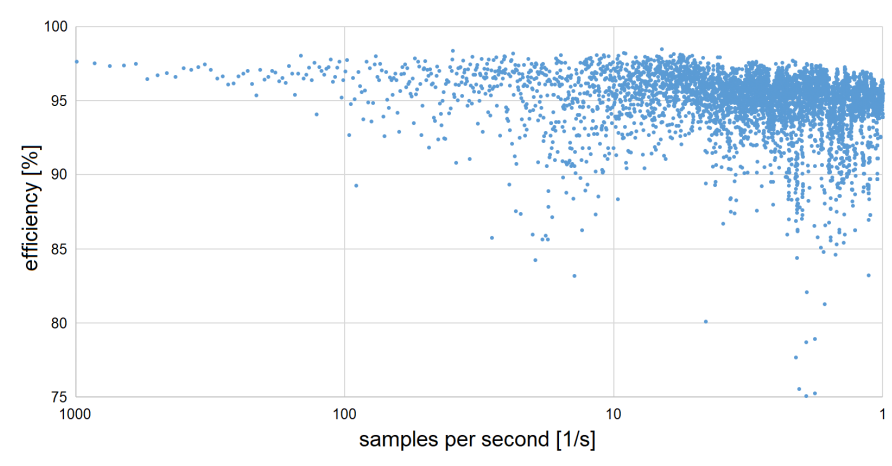

Fig. 15. $\mathrm{P} \& \mathrm{O}$ algorithm efficiency $\left(\eta_{m p p t}\right), 31^{\text {st }}$ of July $(v=30 \mathrm{~km} / \mathrm{h})$

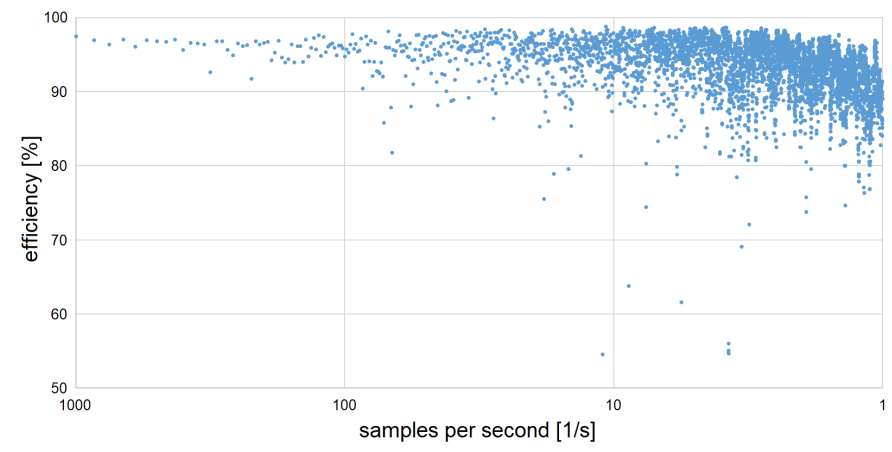

Fig. 16. $P \& O$ algorithm efficiency $\left(\eta_{m p p t}\right), 31^{\text {st }}$ of July $(v=40 \mathrm{~km} / \mathrm{h})$

$P_{\text {out }}$ and updating the operating voltage $\left(V_{o p}\right)$ of the $\mathrm{P} \& \mathrm{O}$ algorithm. However, as mentioned above, due different types and times of shading conditions of the installed measurement probes, it is unlikely that the reference PV cell or panel will be exposed to the same solar radiation level as the main PV panel. Hence, the reference PV cell or panel would provide the wrong information to the $\mathrm{P} \& \mathrm{O}$ algorithm.

\section{DISCUSSION}

In real-world environmental conditions, the solar radiation level can vary in different ways and is dependent on the geographical location, ambient conditions (air temperature, relative humidity, wind and gust speed, particles and aerosols in the air), vehicle speed, and the surrounding environment such as tree-avenues and buildings. Furthermore, the efficiency of the MPPT algorithm $\left(\eta_{m p p t}\right)$ depends on the sample position at which the $\mathrm{P} \& \mathrm{O}$ algorithm updates the vital parameter $P_{\text {out }}$. Hence, a decrease in efficiency is not always consistent with a decrease in sampling vital MPPT parameters.

It was found out that a change in ambient conditions (Fig. 14) or increase in the speed of the vehicle (Fig. 16) can result in a decrease of the efficiency of the $\mathrm{P} \& \mathrm{O}$ algorithm. It is worth noting that the conventional $\mathrm{P} \& \mathrm{O}$ algorithm is designed for the control of the operating voltage $\left(V_{o p}\right)$ of stationary $\mathrm{PV}$ installations and not for moving PV installations. Furthermore, improvements of the $\mathrm{P} \& \mathrm{O}$ algorithm focus on an increase of the efficiency of the algorithm $\left(\eta_{m p p t}\right)$ at steady-state conditions [33], [34]. A change for example in the size of the perturbation voltage $(\Delta V)$ do not result in a consistent improvement of $\eta_{m p p t}$ for moving PV installations.

\section{CONCLUSION}

For stationary PV installations, a sampling period of 10 $\mathrm{s}$ is suitably high enough, but a faster sampling rate of 500 samples/s is recommended for moving PV installations e.g. on a vehicle or bicycle. Exact values, for example for upward/downward ramps and sampling rates, depend on the circumstances of the region in which photovoltaics are utlised. Our data shows that fast ramps $\left(r_{\lambda, u}\right.$ and $\left.r_{\lambda, d} \approx 100 \frac{\mathrm{W}}{\mathrm{m}^{2}} / \mathrm{s}\right)$ occur more frequently than slow ramps during recurrent changes between sunlight and clouds. For moving PV installations, upwards/downwards ramps are as large as $100 \frac{\mathrm{W}}{\mathrm{m}^{2}} / \mathrm{ms}$.

If photovoltaics are mounted on a car driving in a city, the shadowing will be instantaneous. The effect on the $\mathrm{P} \& \mathrm{O}$ algorithm was studied. The efficiency of the algorithm $\left(\eta_{m p p t}\right)$ can drop from about $99 \%$ (achieved for stationary PV installations) to as low as 55\% (in the case of moving PV installations). For moving PV installations, the update frequency of vital parameters is critical. We suggest using environmental data directly for PV simulation models, which also include the functionality to simulate MPPT. In this way, the degree of efficiency of photovoltaic power systems can be analysed. Common MPPT test profiles used for stationary PV installations are not suitable for moving PV installations.

\section{ACKNOWLEDGMENT}

The authors would like to thank Maija Schuss for her help and support in setting up and carrying out the measurements.

\section{ACKNOWLEDGMENT}

\section{REFERENCES}

[1] D.P. van Vuuren, N. Nakicenovic, K. Riahi, A. Brew-Hammond, D. Kammen, V. Modi, and K. Smith, "An energy vision: The transformation towards sustainability - interconnected challenges and solutions", Current Opinion in Environmental Sustainability, vol. 4, issue: 1, pp. 18-34, 2012.

[2] S. Mekhilef, R. Saidur, and A. Safari, "A review on solar energy use in industries", Renewable and Sustainable Energy Reviews, vol. 15, issue: 4, pp. 1777-1790, 2011.

[3] C. Schuss, H. Gall, K. Eberhart, H. Illko, and B. Eichberger, "Alignment and Interconnection of Photovoltaics on Electric and Hybrid Electric Vehicles", Proceedings of the IEEE International Instrumentation and Measurement Technology Conference (I2MTC), pp. 524-527, 2014.

[4] G.C. Mouli, P. Bauer, and M. Zeman, "System design for a solar powered electric vehicle charging station for workplaces", Applied Energy, vol. 168, pp. 434-443, 2016.

[5] C. Schuss, B. Eichberger, and T. Rahkonen, "Impact of Sampling Interval on the Accuracy of Estimating the Amount of Solar Energy", Proceedings of the IEEE International Instrumentation and Measurement Technology Conference (I2MTC), pp. 1355-1360, 2016.

[6] C. Alippi, and C. Galperti, "An Adaptive System for Optimal Solar Energy Harvesting in Wireless Sensor Network Nodes", IEEE Transactions on Circuits and Systems I: Regular Papers, vol. 55, issue: 6, pp. $1742-$ 1750, 2008.

[7] L. Cai, N. Dai, Z. and Tan, "Research on mathematical model and calculation simulation of wireless sensor solar cells in Internet of Things", EURASIP Journal on Wireless Communications and Networking, vol. 1, p. $116,2018$.

[8] C. Schuss, and T. Rahkonen, "Adaptive Photovoltaic Cell Simulation with Maximum Power Point Tracking Simulation for Accurate Energy Predictions", NORCHIP 2011, article number 6126721, pp. 1-4, 2011.

[9] H.-L. Tsai, "Insolation-oriented model of photovoltaic module using Matlab/Simulink", Solar Energy, vol. 84, issue 7, pp. 1318-1326, 2010.

[10] C. Schuss, B. Eichberger, and T. Rahkonen, "Measurement and Verification of Photovoltaic (PV) Simulation Models", Proceedings of the IEEE International Instrumentation and Measurement Technology Conference (I2MTC), pp. 188-193, 2013. 
[11] L. Cristaldi, M. Faifer, M. Rossi, and F. Ponci, "A Simple Photovoltaic Panel Model: Characterization Procedure and Evaluation of the Role of Environmental Measurements", IEEE Transactions on Instrumentation and Measurement, vol. 61, issue: 10, pp. 2632-2641, 2012.

[12] M.G. Villalva, and E.R. Filho, "Analysis and Simulation of the P\&O MPPT Algorithm Using a Linearized PV Array Model", 35th Annual Conference of the IEEE Industrial Society, IECON 2009, pp. 231-235, 2009.

[13] K. Araki, L. Ji, G. Kelly, and M. Yamaguchi, "To Do List for Research and Development and International Standardization to Achieve the Goal of Running a Majority of Electric Vehicles on Solar Energy", Coatings, vol. 8 , issue: 7 , pp. $251,2018$.

[14] T.L. Gibson, and N.A. Kelly, "Solar photovoltaic charging of lithiumion batteries", IEEE Vehicle Power and Propulsion Conference (VPPC), pp. 310-316, 2009.

[15] D.P. Birnie III, "Analysis of energy capture by vehicle solar roofs in conjunction with workplace plug-in charging", Solar Energy, vol. 125, pp. 219-226, 2016.

[16] T. Masuda, K. Araki, K. Okumura, S. Urabe, Y. Kudo, K. Kimura, T. Nakado, A. Sato, and M. Yamaguchi, "Static concentrator photovoltaics for automotive applications", Solar Energy, vol. 146, pp. 523-531, 2017.

[17] K. Araki, C. Algora, G. Siefer, K. Nishioka, R. Leutz, S. Carter, S. Wang, S. Askins, L. Ji, and G. Kelly, "Standardization of the CPV and car-roof PV technology in 2018 - Where are we going to go?", AIP Conference Proceedings, vol. 2012, no. 1, p. 070001, 2018.

[18] Y. Ota, T. Masuda, K. Araki, and M. Yamaguchi, "Curve-Correction Factor for Characterization of the Output of a Three-Dimensional Curved Photovoltaic Module on a Car Roof", Coatings, vol. 8, issue: 12, pp. 432, 2018.

[19] T.T. Nguyen, H.W. Kim, G.H. Lee, and W. Choi, "Design and implementation of the low cost and fast solar charger with the rooftop PV array of the vehicle", Solar Energy, vol. 96, pp. 83-95, 2013.

[20] C. Schuss, B. Eichberger, and T. Rahkonen, "Impact of Solar Radiation on the Output Power of Moving Photovoltaic (PV) Installations", Proceedings of the IEEE International Instrumentation and Measurement Technology Conference (I2MTC), pp. 1297-1302, 2018.

[21] B. Andò, S. Baglio, A. Pistorio, G.M. Tina \& C. Ventura, "Sentinella: Smart Monitoring of Photovoltaic Systems at Panel Level", IEEE Transactions on Instrumentation and Measurement, vol. 64, issue: 8, pp. 21882199,2015

[22] T. Esram, and P.L. Chapman, "Comparison of Photovoltaic Array Maximum Power Point Tracking Techniques", IEEE Transactions on Energy Conversion, vol. 22, issue: 2, pp. 439-449, 2007.

[23] M. Ropp, J. Cale, M. Mills-Price, M. Scharf, and S.G. Hummel, "A test protocol to enable comparative evaluation of maximum power point trackers under both static and dynamic irradiance", 37th IEEE Photovoltaic Specialists Conference (PVSC) 2011, article number 6185961, 2011.

[24] R. Bründlinger, N. Henze, H. Häberlin, B. Burger, A. Bergmann, and F. Baumgartner, "prEN 50530 - the new European Standard for Performance Characterization of PV Inverters", 24th European Photovoltaic Solar Energy Conference 2009. [Online]. Available: http://labs.ti.bfh.ch/ fileadmin/user_upload/lab1/pv/publikationen/4EP.1.2_EUPVSEC_Paper_ EN50530_PV_inverter_Performance_-final-_090924.pdf

[25] C. Schuss, B. Eichberger, and T. Rahkonen, "Design Specifications and Guidelines for Efficient Solar Chargers of Mobile Phones", $11^{\text {th }}$ International Multi-Conference on Systems, Signals Devices (SSD), pp. $1-5,2014$.

[26] C. Schuss, T. Kotikumpu, B. Eichberger, and T. Rahkonen, "Impact of Dynamic Environmental Conditions on the Output Behaviour of Photovoltaics", $20^{\text {th }}$ IMEKO TC4 International Symposium and $18^{\text {th }}$ International Workshop on ADC Modelling and Testing, pp. 993-998, 2014.

[27] K.D. Kanniah, J. Beringer, P. North, and L. Hutley, "Control of atmospheric particles on diffuse radiation and terrestrial plant productivity: A review", Progress in Physical Geography, vol. 36, issue: 2, pp. 209-237, 2012.

[28] J.K. Bishop, and W.B. Rossow, "Spatial and Temporal Variability of Global Surface Solar Irradiance", Journal of Geophysical Research: Oceans, vol. 96, pp. 16839-16858, 1991.

[29] S.B. Idso, "Holocoenotic Analysis of Environment-Plant Relationships", Minnesota Agricultural Experiment Station, 1968.

[30] A. Mellit, and A.M. Pavan, "A 24-h forecast of solar irradiance using artificial neural network: Application for performance prediction of a gridconnected PV plant at Trieste, Italy", Solar Energy, vol. 84, issue: 5, pp. 807-821, 2010.
[31] J.L. De Souza, R.M. Niccio, and M.A.L. Moura, "Global solar radiation measurements in Macei, Brazil", Renewable energy, vol. 30, issue: 8, pp.1203-1220, 2005.

[32] M. Hofmann, and G. Seckmeyer, "A New Model for Estimating the Diffuse Fraction of Solar Irradiance for Photovoltaic System Simulations", Energies, vol. 10, issue: 2, p. 248, 2017.

[33] N. Femia, G. Petrone, G. Spagnuolo, and M. Vitelli, "Optimization of perturb and observe maximum power point tracking method", IEEE Transactions on Power Electronics, vol. 20, issue: 4, pp.963-973, 2005.

[34] J. Ahmed, and Z. Salam, "An improved perturb and observe (P\&O) maximum power point tracking (MPPT) algorithm for higher efficiency", Applied Energy, vol. 150, pp. 97-108, 2015.

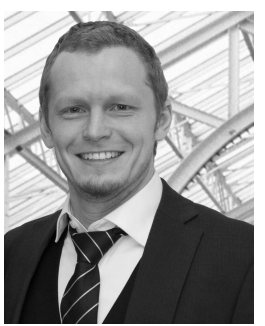

Christian Schuss (S'11-M'17) was born in Lienz, Austria, in 1983. He received the Dipl.-Ing. (Hons.) degree in information technology and the Dr.Techn. degree in automotive electronics from the Graz University of Technology, Graz, Austria, in 2010 and 2014, respectively, and the D.Sc. (Tech.) degree in electronics design from the University of Oulu, Oulu, Finland in 2017. He is currently a Research and Teaching Assistant with the Circuits and Systems (CAS) Research Unit, University of Oulu, Oulu, Finland. His current research interests include renewable energy resources, energy harvesting and automotive electronics.

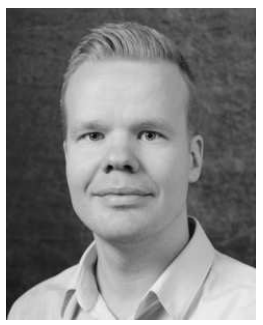

Tapio Fabritius received the M.S. and D.Sc. (Tech.) degrees in electrical engineering from the University of Oulu, Oulu, Finland, in 2003 and 2007, respectively. He was a Visiting Researcher with the Computational Optics Group, University of Tsukuba, Tsukuba, Japan, from 2006 to 2007. In 2009, he was conducting research with the Flexible Display Center, Tempe, AZ, USA. Since 2012, he has been the Research Director of PrintoCent, Oulu. He is currently the Head of the Printed Intelligence Group with the OPEM Research Unit, University of Oulu. He has co-authored over 60 papers. His current research interests include manufacturing and characterization of printed intelligence.

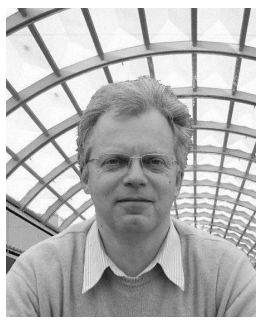

Bernd Eichberger was born in Bruck an der Mur, Austria, in 1961. He received the Diploma and Dr.Techn. (Hons.) degrees in electrical engineering from the Graz University of Technology, Graz, Austria, in 1990 and 1994, respectively.

$\mathrm{He}$ is currently a Professor with the Institute of Electronic Sensor Systems, Graz University of Technology. His current research interests include industrial and automotive electronic circuits and systems, new test and measurement principles, electronic engine control units, and fuel cell and lithiumion battery monitoring and diagnosis.

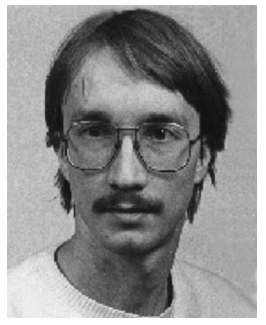

Timo Rahkonen (S'88-M'90) was born in Jyväskylä, Finland, in 1962. He received the Diploma Engineering, Licentiate, and D.Tech. degrees from the University of Oulu, Oulu, Finland, in 1986, 1991, and 1994, respectively.

$\mathrm{He}$ is currently a Professor of Circuit Theory and Circuit Design with the CAS Resaerch Unit and Infotech Oulu, University of Oulu, where he conducts research on linearization and error correction techniques for RF power amplifiers and $\mathrm{A} / \mathrm{D}$ and $\mathrm{D} / \mathrm{A}$ converters. 